\title{
Desenvolvimento de Materiais para a Descontaminação FOTOCATALÍtica dE ÁGUAS
}

\author{
Cláudia Gomes Silva*
}

\begin{abstract}
A primeira contribuição no campo da fotocatálise heterogénea deu-se em 1972 com o trabalho pioneiro de Fujishima e Honda, em que ficou demonstrada a possibilidade de formação de hidrogénio através da cisão fotoelectroquímica da água utilizando um fotoânodo de $\mathrm{TiO}_{2}$ e um cátodo de platina. Esta descoberta abriu novas fronteiras para o uso do dióxido de titânio como fotocatalisador noutros tipos de aplicações. Quatro anos mais tarde, o grupo de J. H. Carey publicou pela primeira vez um estudo sobre a degradação fotocatalítica de moléculas orgânicas (bifenilo e derivados de clorobifenilo) na presença de $\mathrm{TiO}_{2}$. Desde então inúmeros trabalhos têm sido publicados sobre o desenvolvimento e utilização de catalisadores à base de $\mathrm{TiO}_{2}$ em processos fotocatalíticos de descontaminação de águas residuais. Este trabalho pretende ser um contributo na área do desenvolvimento de fotocatalisadores à base de $\mathrm{TiO}_{2}$, concretamente compósitos de nanotubos de carbono- $\mathrm{TiO}_{2}$, e sua aplicação no tratamento de águas contaminadas com polventes orgânicos.
\end{abstract}

\section{Água: A Problemática Ambiental}

A protecção ambiental e a correcção de problemas associados ao meio ambiente são questões fundamentais no que respeita à melhoria da qualidade de vida e a um desenvolvimento sustentável. A água encontra-se presente em múltiplas actividades humanas como o uso doméstico, agrícola, industrial e na produção de energia. Em média, nos países europeus, o uso doméstico representa apenas $21 \%$ do consumo total de água, enquanto que $25 \%$ é utilizada na agricultura e cerca de $54 \%$ em actividades industriais e na produção de energia [1]. Associada a cada uma destas actividades existem diferentes tipos de poluição e de poluentes. Na região ibérica, os principais processos industriais geradores de águas residuais incluem os das industrias petroquímica, de síntese química, têxtil, farmacêutica, agroquímica, do papel e alimentar.

Laboratório de Catálise e Materiais, Laboratório Associado LSRE/LCM, Departamento de Engenharia Química, Faculdade de Engenharia, Universidade do Porto, R. Dr. Roberto Frias s/n 4200-465 Porto. E-mail: cgsilva@fe.up.pt
Os processos biológicos são os mais utilizados em sistemas de tratamento de efluentes líquidos. Apesar de serem mais naturais e de fácil implementação, a sua maior desvantagem advém da produção de grandes quantidades de lamas (geralmente proporcionais à quantidade de água tratada). Adicionalmente, existem poluentes que apresentam uma grande estabilidade química e biológica sendo dificilmente degradados através dos usuais tratamentos biológicos. Nesses casos torna-se necessário recorrer a sistemas mais eficientes do que os processos de tratamento de águas convencionais. Nas últimas décadas muita investigação tem sido dedicada ao desenvolvimento de uma classe particular de técnicas de oxidação à qual se designou de Processos Avançados de Oxidação Química (AOP, segundo a designação anglo-saxónica Advanced Oxidation Processes) [2]. Os AOP aplicados à oxidação de compostos orgânicos em meio aquoso baseiamse na formação de intermediários altamente reactivos, que conduzem à degradação de vários tipos de poluentes. De entre os AOP destacam-se os processos de oxidação química $\left(\mathrm{O}_{3}, \mathrm{O}_{3} /\right.$ $\mathrm{H}_{2} \mathrm{O}_{2}$, Fenton), de oxidação fotoquímica $\left(\mathrm{UV} / \mathrm{O}_{3}, \mathrm{UV} / \mathrm{H}_{2} \mathrm{O}_{2}\right)$ e os processos fotocatalíticos (UV/TiO ${ }_{2}$, Foto-Fenton). Todos eles têm em comum a intervenção de um agente químico altamente eficaz, gerado normalmente a partir de uma espécie primária comum, o radical hidroxilo $\left(\mathrm{HO}^{*}\right)$. Este radical é extremamente reactivo e muito pouco selectivo, o que, aliado ao seu elevado poder oxidante, o torna capaz de degradar a maioria dos compostos orgânicos responsáveis pela contaminação de águas residuais.

Desde os trabalhos pioneiros de $\mathrm{Fu}$ jishima e Honda [3] e do grupo de J. H. Carey [4], muito caminho foi já percorrido. Tendo em conta o actual desenvolvimento e a rápida expansão das tecnologias ópticas e fotónicas, os processos fotoquímicos posicionam-se numa situação privilegiada para competir com as restantes tecnologias disponíveis. Uma vez que a luz e a água estão na base da maioria das reacções que condicionam a vida no planeta, não será de espantar que a própria natureza já tenha posto a funcionar mecanismos fotoquímicos de regeneração; daí grande parte do interesse na via fotoquímica e na sua aplicação a questões ambientais. A maior limitação deste tipo de processos consiste no rendimento 
energético, normalmente desfavorável quando se utilizam fontes de radiação altamente energéticas na gama do ultravioleta (UV). Contudo, o rápido desenvolvimento das tecnologias de captação e conversão de energia solar vieram viabilizar muitos dos processos descritos nos finais do século $X X$ para fontes luminosas artificiais $[5,6]$. Serão provavelmente estes processos que terão uma palavra a dizer num futuro próximo, sobretudo nas economias dos países tecnologicamente desenvolvidos e que beneficiem de uma taxa anual de exposição solar elevada.

\section{O Processo Fotocatalítico}

Os processos de oxidação fotoquímica catalisados por materiais semicondutores aplicados no tratamento de água para consumo humano e de águas residuais, têm vindo a revelar um óptimo desempenho na mineralização de uma grande variedade de compostos orgânicos e inorgânicos. O termo "fotocatálise", composto pelo prefixo "foto" (do grego, luz) e pela palavra "catálise", diz respeito a um tipo de reacções químicas de oxidação, iniciadas pela absorção de luz por meio de um agente promotor da reacção (o catalisador), que após tomar parte na mesma, tem a capacidade de se regenerar e recomeçar um novo ciclo de reacções idênticas. A sua capacidade regenerativa não é constante, o que se traduz numa perda de actividade que tem de ser reposta à custa da substituição mais ou menos frequente do catalisador. Nos processos fotocatalíticos heterogéneos são utilizados meios sólidos no seio do líquido (ou gás) contendo o poluente, e que actuam como catalisadores. Neste caso as reacções de degradação oxidativa requerem a presença de três constituintes elementares: uma superfície catalítica fotossensível (normalmente o semicondutor inorgânico), uma fonte de fotões de energia adequada (luz artificial ou solar) e um agente oxidante (normalmente oxigénio). A reacção fotocatalítica é iniciada pela activação do catalisador à custa de um fotão com energia suficiente para excitar um electrão do semicondutor da banda de valência (BV) para a banda de condução (BC), originando assim uma separação de carga capaz de promo-

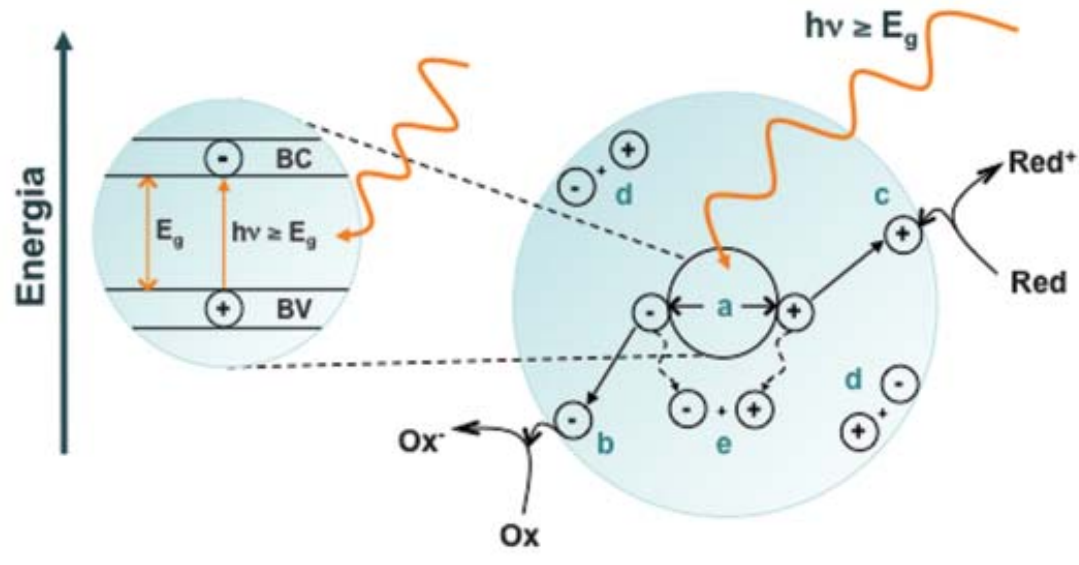

Figura 1 - Principais processos que ocorrem na partícula de semicondutor: (a) fotogeração do par electrão/lacuna; (b) difusão do receptor de electrões e sua redução na superfície do semicondutor; (c) oxidação do dador de electrões na superfície da partícula; (d) e (e) recombinação dos pares electrão/ lacuna à superfície e no seio da partícula, respectivamente

ver reacções de redução e oxidação à sua superfície (Figura 1).

Os semicondutores geralmente utilizados como fotocatalisadores consistem em materiais do tipo óxidos ou sulfuretos metálicos como por exemplo óxidos de titânio, zinco, cério, tungsténio e sulfuretos de cádmio e de zinco. O dióxido de titânio destaca-se como fotocatalisador de eleição uma vez que apresenta um elevado poder oxidante, baixo custo relativo, fotoestabilidade, não-toxicidade e insolubilidade sob a maioria das condições, características que o tornam um material muito atractivo para aplicações ambientais, em particular na degradação de poluentes orgânicos. Contudo, apresenta duas principais limitações que restringem o seu uso eficiente: um baixo rendimento fotónico e um gradiente energético de $3.2 \mathrm{eV}$, requerendo assim excitação na região do UV para activação do processo, o que corresponde a menos de $10 \%$ da intensidade total da radiação solar. Com o objectivo de ultrapassar estas limitações, imensa investigação tem sido dedicada no sentido de aumentar a eficiência do $\mathrm{TiO}_{2}$ recorrendo-se a várias técnicas como a dopagem com iões metálicos e não metálicos, a fotosensibilização com corantes, a deposição de metais nobres, a mistura com outros materiais semicondutores e a adição de suportes [7].

\section{Desenvolvimento de Fotocatalisa- DORES}

Uma das estratégias utilizadas para aumentar a actividade do dióxido de titânio, consiste na introdução de uma segunda fase constituída por outro tipo de materiais como zeólitos, sílica, alumina ou materiais de carbono.

Normalmente, a introdução dessa fase acontece no processo de síntese dando origem à formação de materiais compósitos. Esta estratégia permite: i) a imobilização da fase activa $\left(\mathrm{TiO}_{2}\right)$; ii) o aumento da área específica iluminada; iii) o aumento da área superficial do material resultante e da sua capacidade de adsorção; iv) o aumento da actividade fotocatalítica através da criação de sinergias entre as duas fases; v) maior facilidade na separação do catalisador, quando usado em suspensão.

De entre os vários tipos de materiais utilizados na produção de fotocatalisadores compósitos, tem sido dedicada uma atenção especial aos compósitos de $\mathrm{TiO}_{2}$ produzidos com materiais de carbono como carvões activados, fibras de carbono e nanotubos de carbono. Actualmente, os nanotubos de carbono (CNT, da expressão anglossaxónica Carbon Nanotubes) têm sido objecto de intensa investigação, sendo considerados como fortes candidatos a substituir os carvões activados amplamente utilizados como suportes catalíticos, devido à combinação das suas características electrónicas, mecânicas, térmicas e de adsorção [8]. Vários estudos têm demonstrado que os catalisadores compósitos de CNT$\mathrm{TiO}_{2}$ exibem melhores eficiências fotocatalíticas do que o $\mathrm{TiO}_{2}$ puro, quer sob irradiação no UV, como na gama do visível [9-14]. 
A preparação deste tipo de catalisadores compósitos pode ser levada a cabo por um variado conjunto de técnicas como a deposição química em fase de vapor, hidrólise em condições supercríticas, impregnação, processos hidrotérmicos, método sol-gel, entre outras.

O método sol-gel apresenta várias vantagens em relação aos restantes processos, nomeadamente a facilidade de execução, a pureza dos materiais obtidos e o fácil controlo da composição dos materiais. Como precursores da fase de $\mathrm{TiO}_{2}$ são geralmente utilizados alcóxidos como o etóxido, o butóxido e o isopropóxido de titânio. $\mathrm{O}$ processo inicia-se com um passo de hidrólise, normalmente catalisado em meio ácido, seguido por um passo de condensação das cadeias poliméricas (Figura 2). A etapa final consiste no tratamento térmico dos materiais com vista à cristalização da fase de $\mathrm{TiO}_{2} \mathrm{e}$ à remoção da fracção orgânica proveniente do precursor.

Na produção de materiais compósitos, os nanotubos de carbono são introduzidos durante a fase de hidrólise. Neste processo, a própria química superficial dos nanotubos de carbono tem um papel fundamental nas propriedades finais do compósito.

Os grupos fenol e ácido carboxílico presentes na superfície dos nanotubos (existentes no material original ou introduzidos através de tratamentos adequados) constituem pontos de ancoragem do precursor alcóxido hidrolisado através de reacções de oxolação e de esterificação, respectivamente (Figura 3).

No sentido de interpretar a acção da fase de CNT nos compósitos CNT$\mathrm{TiO}_{2}$ são normalmente propostos três mecanismos distintos: i) os nanotu-
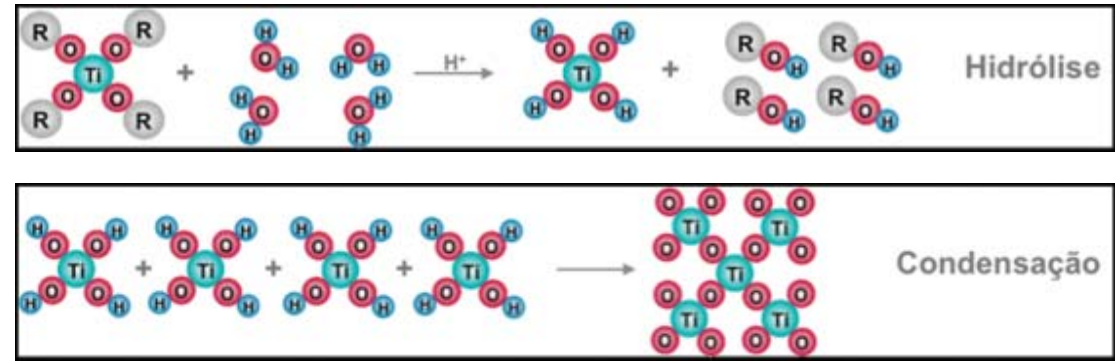

Figura 2 - Síntese de $\mathrm{TiO}_{2}$ pelo método sol-gel (R refere-se ao grupo alcóxido do precursor)

bos de carbono actuam como coadsorventes, transferindo o poluente orgânico para a fase de $\mathrm{TiO}_{2}$, onde ocorre a sua degradação; ii) actuam como meio dispersante das cristalites de $\mathrm{TiO}_{2}$, evitando a sua aglomeração e a formação de partículas de grandes dimensões; iii) acção como agente fotosensibilizador, injectando ou recebendo electrões para a (ou da) fase de $\mathrm{TiO}_{2}$. Vários estudos têm vindo a demonstrar que de entre os três processos, o que revela ter um maior importância é a acção dos nanotubos como fotosensibilizadores [9-14].

Tendo em conta a natureza semicondutora deste tipo de materiais de carbono, os nanotubos podem absorver luz e iniciar uma transferência fotoinduzida de electrões para a banda de condução do $\mathrm{TiO}_{2}$ (Figura 4a). Simultaneamente, após excitação da fase de $\mathrm{TiO}_{2}$, electrões da banda de valência são transferidos para a fase de carbono, dando origem à formação de lacunas (Figura 4b). Essas lacunas constituem centros de formação de radicais hidroxilo, que são os responsáveis pela degradação dos compostos orgânicos.

\section{Degradação Fotocatalítica de Compostos Fenólicos}

A eficiência dos materiais compósitos de $\mathrm{CNT}_{-} \mathrm{TiO}_{2}$ em processos de degra-

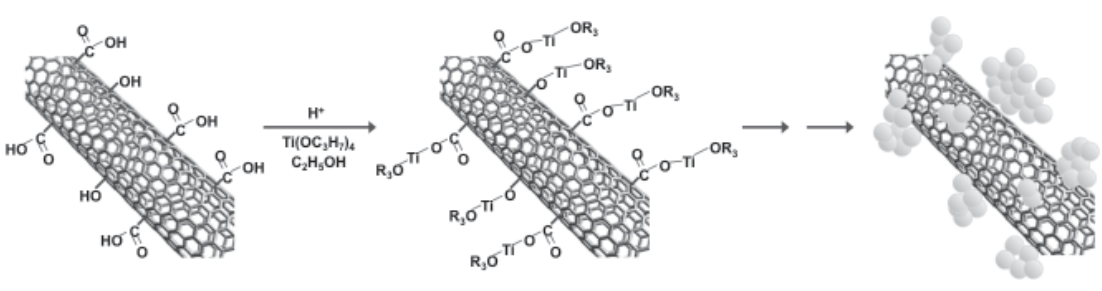

Figura 3 - Formação do compósito CNT-TiO 2 
do para-hidroxibenzóico [14]. O intuito deste estudo consistiu em avaliar o efeito da natureza química dos grupos substituintes presentes na molécula de fenol na eficiência do processo de degradação fotocatalítica utilizando $\mathrm{TiO}_{2}$ e um compósito de CNT-TiO sob irradiação na zona espectral do visível. Deste modo, foi encontrada uma correlação entre as constantes de Hammet $\left(\sigma_{p}^{-}\right)$de cada uma das moléculas orgânicas e a velocidade inicial de remoção de cada um dos compostos, quer utilizando $\mathrm{TiO}_{2}$ como CNT$\mathrm{TiO}_{2}$ como catalisadores (Figura 5). Os resultados obtidos neste estudo revelam que a eficiência do processo fotocatalítico depende não só das propriedades físico-químicas do catalisador, mas também da natureza química das moléculas a degradar. No caso dos fenóis para-substituídos, o processo é favorecido na presença de grupos dadores de electrões, como é o caso do grupo $-\mathrm{NH}_{2}$ na anilina e retardado na presença de substituintes aceitadores de electrões como é o caso dos grupos $-\mathrm{Cl},-\mathrm{COOH}$ e $-\mathrm{NO}_{2}$ nas moléculas de para-clorofenol, áci- do para-hidroxibenzóico e para-nitrofenol, respectivamente.

Este estudo mostra que a eficiência dos catalisadores compósitos CNT$\mathrm{TiO}_{2}$ se revela principalmente em reacções de degradação de compostos com grupos dadores de electrões (grupos activantes), o que confirma a natureza electrofílica das reacções fotocatalisadas por este tipo de materiais.

Com esta contribuição pretende-se abrir horizontes para uma investigação mais intensa ao nível do "design" e utilização de fotocatalisadores para utilização em processos de descontaminação ambiental.

\section{Agradecimentos}

Parte deste trabalho foi desenvolvido ao abrigo dos projectos POCl/ EQU/58252/2004 e POCTI/1181/2003, financiados pela FCT, Programa Operacional (POCTI/POCI) e cofinanciados pelo FEDER. A autora agradece a Bolsa de Doutoramento que Ihe foi atribuída pela FCT (SFRH/ BD/16966/2004).

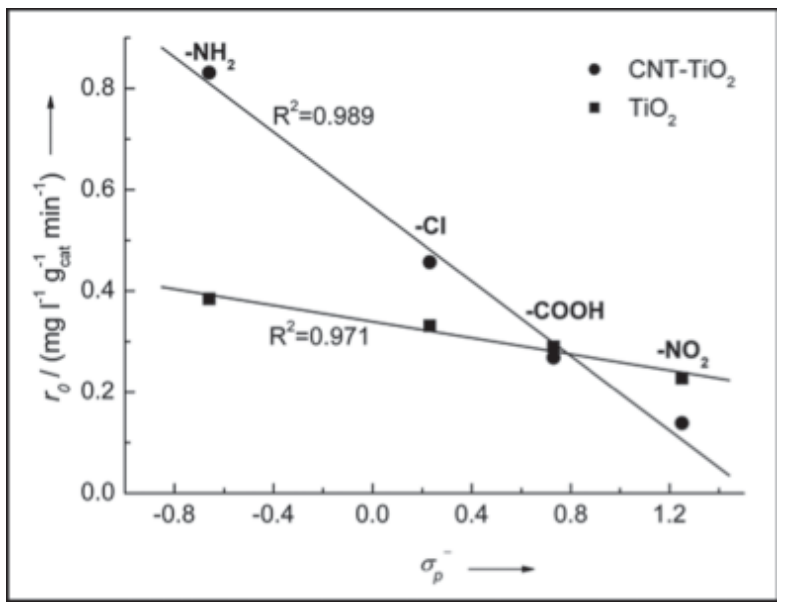

Figura 5 - Relação entre a velocidade inicial de degradação $\left(r_{0}\right)$ e a constante de Hammet $\left(\sigma_{p}{ }^{-}\right)$para diferentes fenóis para-substituídos (indicados através dos respectivos grupos funcionais) [14]

\section{REFERÊNCIAS}

[1] Water abstractions per sector for the period 1997-2005 Web: http://www. eea.europa.eu/data-and-maps (European Enviroment Agency, acedido em 10-05-2010).

[2] R. Andreozzi, V. Caprio, A. Insola, R. Marotta, Catalysis Today 53 (1999) 51-59.

[3] A. Fujishima and K. Honda, Nature, 238 (1972) 37-38.

[4] J.H. Carey, J. Lawrence, H.M. Tosine, Bulletin of Environmental Contamination \& Toxicology 16 (1976) 697-701.

[5] S. Malato, J. Blanco, A. Vidal, C. Richter, Applied Catalysis B: Environmental 37 (2002) 1-15.

[6] S. Malato, J. Blanco, A. Vidal, D. Alarcon, M.I. Maldonado, J. Caceres, W. Gernjak, Solar Energy 75 (2003) 329336.

[7] U.I. Gaya, A.H. Abdullah, Journal of Photochemistry and Photobiology C: Photochemical Reviews 9 (2008) 1-12.

[8] J.L. Faria, W. Wang, Carbon Materials in Photocatalysis, in Carbon Materials for Catalysis, P. Serp, J.L. Figueiredo (ed.) John Wiley \& Sons (2009), 481506.

[9] W. Wang, P. Serp, P. Kalck, J.L. Faria, Applied Catalysis B: Environmental 56 (2005) 305-312.

[10] W. Wang, P. Serp, P. Kalck, J.L. Faria, Journal of Molecular Catalysis A: Chemical 235 (2005) 194-199.

[11] W. Wang, P. Serp, P. Kalck, C.G. Silva, J.L. Faria, Materials Research Bulletin 43 (2008) 958-967.

[12] B. Gao, G.Z. Chen, G.L. Puma, Applied Catalysis B: Environmental $\mathbf{8 9}$ (2009) 503-509.

[13] Y.J. Xu, Y.B. Zhuang, X.Z. Fu, Journal of Physical Chemistry C 114 (2010) 2669-2676.

[14] C.G. Silva, J.L. Faria, ChemSusChem 3 (2010) 609-618.

\section{Vá a www.spq.pt}

Torne-se Sócio da Sociedade Portuguesa de Química e beneficie de:

- Pertencer a uma comunidade científica dinâmica;

- Receber o boletim "QUÍMICA";

- Descontos nos Encontros promovidos pela SPQ;

- Descontos nas publicações da SPQ;

- Protocolos assinados entre a SPQ e outras entidades;

- Participar na promoção da Química;

- Apoiar uma Sociedade Científica. 